\title{
Estimation of SLR station coordinates by means of SLR measurements to kinematic orbit of LEO satellites
}

Jinyun Guo ${ }^{1,2^{*}}$, Youcun Wang ${ }^{1}$, Yi Shen ${ }^{1}$, Xin Liu' ${ }^{1}$, Yu Sun ${ }^{3}$ and Qiaoli Kong ${ }^{1,2}$

\begin{abstract}
Generally, the dynamical model is used to estimate coordinates of satellite laser ranging (SLR) stations. In this paper, we put forward a kinematic method to estimate the coordinates of SLR stations by using global navigation satellite system (GNSS) technique onboard a low Earth orbiting (LEO) satellite. We applied it to the processing of SLR and GNSS observations of the GRACE-A satellite from January to December 2012. We found that the LEO satellite as a spacebased connection between SLR and GNSS techniques allowed the precise estimation of SLR site positions with the agreement level of 2-3 cm with respective to SLRF2014. The SLR network can be attached to the IGS network at the centimeter level. The results show that the proposed method is feasible for determining the coordinates of SLR stations as an idea for the satellite-based integration of different space geodetic techniques.
\end{abstract}

Keywords: Satellite laser ranging, Global navigation satellite system, Low Earth orbiting satellite, Kinematic orbit, Space-based connection

\section{Introduction}

The building and maintenance of International Terrestrial Reference Frame (ITRF), as the realization of the International Terrestrial Reference System (ITRS), is completed by the International Earth Rotation and Reference Systems Service (IERS). The International Union of Geodesy and Geophysics (IUGG) has formally recommended and adopted the ITRF as the basis of the Earth science applications (Altamimi et al. 2011). The ITRF is regularly updated from newly accumulated data with the improved analysis strategies (Altamimi et al. 2016). At present, the adopted techniques for the ITRF, namely Global Navigation Satellite Systems (GNSS), satellite laser ranging (SLR), very long baseline interferometry (VLBI) and Doppler orbitography radiopositioning integrated by Satellite (DORIS), have developed their independent scientific services in the International Association of Geodesy (IAG). They work as technique

\footnotetext{
*Correspondence: jinyunguo1@126.com

${ }^{1}$ College of Geodesy and Geomatics, Shandong University of Science and Technology, Qingdao 266590, China

Full list of author information is available at the end of the article
}

centers in the IERS: International GNSS Service (IGS) (Dow et al. 2009), International Laser Ranging Service (ILRS) (Pearlman et al. 2002), International VLBI Service (IVS) (Schlüter and Behrend 2007) and International DORIS Service (IDS) (Willis et al. 2010). In view of the technique-dependent systematic effects, the combination of solutions from different techniques is hard to accomplish (Ray 2000). According to Rothacher (2000), the challenging subject involving multiple geodetic techniques' integration should be solved at the following three different levels: parameter estimation, observation model and station network. At the station network level, the IERS fundamental sites (colocated sites) can give the only effective solutions for the multi-technique integration (Ray 2000; Munghemezulu et al. 2014; Glaser et al. 2015; Hellerschmied et al. 2018). The inter-technique link is the terrestrial ties obtained from ground geodetic measurements of reference points for different space geodetic instruments (Ray 2000). The combination is completed by providing the known official ties with the appropriate variance information (Ray 2000; Glaser et al. 2015). The determination of eccentricity vectors 
of colocated ITRF sites is a mandatory task (Rothacher 2000; Sarti et al. 2004; Gong et al. 2014).

The SLR observations to low Earth orbiting (LEO) satellites are ignored in the procedure used for the determination ITRF for many years (Schillak and Wnuk 2003; Altamimi et al. 2007; Coulot et al. 2010; Thaller et al. 2011; Altamimi et al. 2016; Ebauer 2017; Sośnica et al. 2018). In the latest released ITRF2014, the solution accuracy of reference frame origin obtained from SLR is at the level of better than $3 \mathrm{~mm}$ at epoch 2010.0 and better than $0.2 \mathrm{~mm}$ per year in the time evolution (Altamimi et al. 2016). The actual computation results of geodynamic satellites are main contribution to the ITRF for SLR technique (Altamimi et al. 2011; Shen et al. 2015; Otsubo et al. 2016). The dynamics is the only method to estimate the SLR-specific realization contributing to the ITRF. The kinematic method is still not considered.

The scale and geocenter estimated from SLR data are the major contribution to the ITRF (e.g., ITRF2005, ITRF2008 and ITRF2014). That is very different for GNSS technique. The computation of scale is associated with the antenna offsets for the GNSS technique (Schmid et al. 2007; Thaller et al. 2011). This explains why a rank deficiency occurs in the normal equation matrix for the GNSS antenna offsets estimation (Ge et al. 2005; Thaller et al. 2011). The inadequate priori model leads to the remaining effect of the solar radiation pressure which directly affects the empirical orbit parameters associated with the geocenter (Ge et al. 2005). The different atmospheric corrections model, the antenna offsets of the GNSS (onboard the satellites and on ground sites) and the different technical equipment can result in some discrepancies between GNSS- and SLR-derived terrestrial reference frames (TRF) (Rothacher 2000). More interests for these discrepancies can be found, e.g., in Rothacher (2000), Ge et al. (2005), Thaller et al. (2015) and Sośnica et al. (2018).

The assessment of the possible contribution of spacebased ties to study the possible contribution of GNSS satellites between SLR and GNSS to the ITRF can be found in Altamimi et al. (2011), Thaller et al. (2011), Sośnica et al. (2015) and Bruni et al. (2017). Thaller et al. (2011) and Sośnica et al. (2015) show that the combination using satellite-based colocations as connection between GNSS and SLR is feasible and allows the estimation of SLR network at the level of $1-2 \mathrm{~cm}$. At present, the only effective combination of SLR and GNSS contributed to the ITRF (besides the Earth rotation parameter) is colocated ground sites (Thaller et al. 2011; Rebischung et al. 2016). Krügel and Angermann (2005) found that differences between the coordinate baselines obtained from different geodetic techniques and the official ties provided by the terrestrial surveying are clear. The reasonable explanation for that is often not solved.

The satellite-borne GNSS technique has the advantages of rich GNSS satellite constellation (simultaneous tracked by multiple satellites) and continuity (high-precision and real-time tracking of LEO satellites) (Li et al. 2009). The satellite-borne GNSS technique has gradually been the primary method of precise orbit determination (POD) for LEO satellites (Švehla and Rothacher 2003; Guo et al. 2012). Kinematics, dynamics and reduced dynamics are the main three methods of LEO satellite POD (Švehla and Rothacher 2003; Li et al. 2009; Guo et al. 2013; Zehentner and Mayer-Gürr 2016). With the performance improvement in the satellite-borne GNSS receiver, the kinematic method can substantially obtain the same results as the reduced dynamic method. As long as the continuous tracking data of GNSS satellites are collected, a kinematic orbit with a relatively high accuracy can be guaranteed (Li et al. 2009; Guo et al. 2013; Zehentner and Mayer-Gürr 2016). For LEO satellites, the kinematic orbit and corresponding variance and covariance information can be applied directly to restore the Earth's gravitational field. It can also be used to refine the atmospheric density and the other related physical models (Švehla and Rothacher 2003; Zehentner and Mayer-Gürr 2016; Tseng et al. 2017). The kinematic method is very suitable for LEO satellites POD such as GOCE, GRACE and CHAMP ( $\mathrm{Li}$ et al. 2009; Zehentner and Mayer-Gürr 2016).

At present, the SLR measurements to LEO satellites were mainly used for precision orbit determination together with other space geodetic techniques or as an independent way of orbit validation (Thaller et al. 2015; Bruni et al. 2017). The inter-technique combination between GNSS and SLR can be performed in a limited way. Up to now, the majority of LEO satellites are tracked by GNSS and SLR. In this study, we present a kinematic method based on the LEO satellite-borne GNSS technique for the precise estimation of SLR station coordinates. As moving stations, LEO satellites can attach the network of SLR sites to the GNSS-derived TRF. This method can quickly estimate the coordinates of SLR stations and also can be used as a means to estimate the scale difference between SLR and GNSS. This method aims at a combination using only a satellite as a connection between different space geodetic techniques. The data of GRACE-A satellite, as one of twin satellites in the Gravity Recovery And Climate Experiment (Tapley et al. 2004), were used. To validate this method, the coordinates of SLR stations are estimated based on GRACE-A data for January-December 2012. 


\section{Methodology}

As shown in Fig. 1, the LEO satellite can be equipped with the satellite-borne GNSS receiver and the SLR retroreflector array. With the help of the GNSS receiver onboard LEO satellite, four or more GNSS satellites are tracked to precisely determine the kinematic orbits of LEO satellite. Simultaneously, the laser retroreflector arrays (LRA) onboard LEO are used to acquire the range measurements of SLR stations. The basic requirements of the kinematic method can be available in practice. The three-dimensional (3D) coordinates of SLR station can be estimated with the least squares method from the multi-epoch LEO kinematic orbits and SLR observations. Figure 2 shows the specific solution process. The first step is to estimate the POD of LEO satellites by using the zero-difference kinematic method. Multi-frequency GNSS data are used, and the orbital coordinates of each epoch are estimated with the least square method. As shown in Fig. 2, the kinematic orbits are derived from GPS observations and GPS orbit products (Švehla and Rothacher 2003). Secondly, the SLR data of LEO satellite are subjected to preliminary processing to obtain the high-precision measurements. The least squares algorithm can be used to estimate the coordinates of SLR stations.

The basic observation equation of SLR station to the LEO satellite at epoch $i$ is

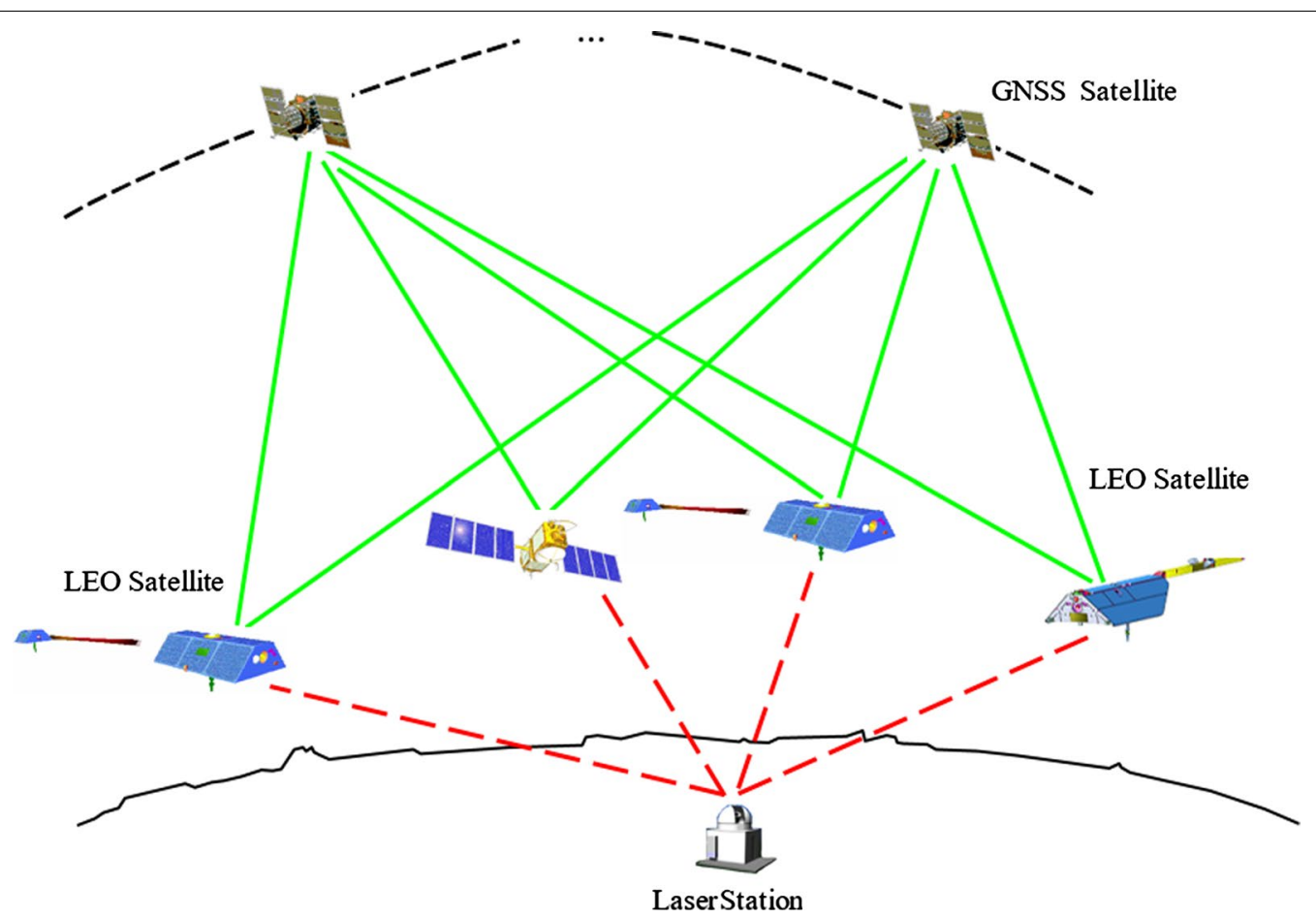

Fig. 1 LEO satellites tracking GNSS satellites and tracked by the SLR simultaneously

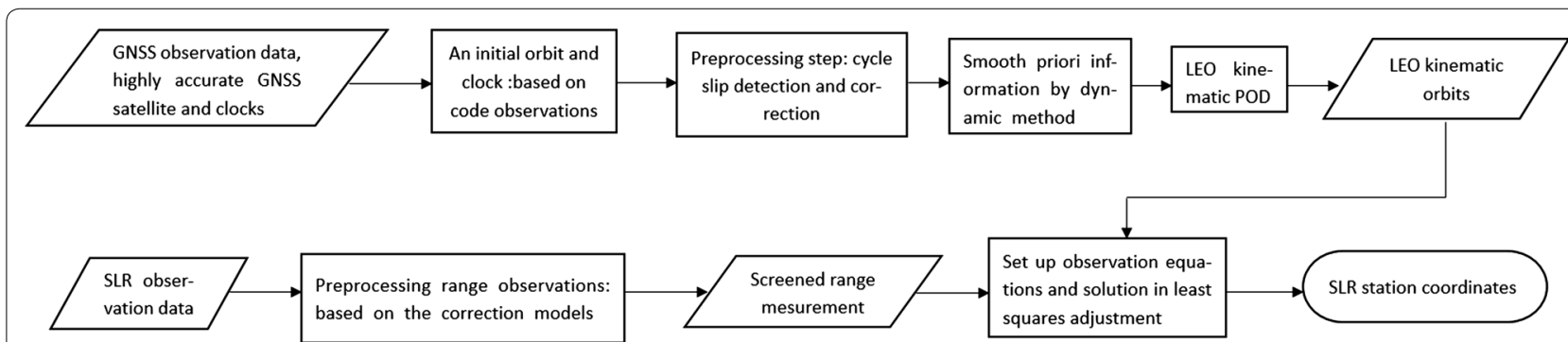

Fig. 2 Flowchart for the coordinate estimation of SLR station with a combination of the LEO satellite kinematic orbit and SLR observations 


$$
\begin{aligned}
\rho_{\mathrm{SLR}}= & \sqrt{\left(x^{i}-x\right)^{2}+\left(y^{i}-y\right)^{2}+\left(z^{i}-z\right)^{2}} \\
& +\Delta \rho_{\mathrm{tro}}+\Delta \rho_{\mathrm{scc}}+\Delta \rho_{\mathrm{rel}} \\
& +\Delta \rho_{\mathrm{syms}}+\Delta \rho_{\mathrm{td}}+\Delta \rho_{\mathrm{cm}}+\varepsilon
\end{aligned}
$$

where $\left(x^{i}, y^{i}, z^{i}\right)$ is the LEO satellite position vector at epoch $i,(x, y, z)$ is the real position vector of SLR station, $\rho_{\mathrm{SLR}}$ is the SLR observation at epoch $i, \Delta \rho_{\text {tro }}$ is the tropospheric delay correction, $\Delta \rho_{\text {scc }}$ is the center-of-mass $(\mathrm{CoM})$ correction of SLR range model, $\Delta \rho_{\text {rel }}$ is the spacetime curvature correction, $\Delta \rho_{\text {syms }}$ is the station-specific range bias and timing offset, $\Delta \rho_{\mathrm{td}}$ is the tidal displacement correction of site position, $\Delta \rho_{\mathrm{cm}}$ is the plate motion correction of the station, and $\varepsilon$ is the residual.

The approximate coordinates of SLR station are $\left(x_{0}, y_{0}, z_{0}\right)$. The linearized observation equation through the Taylor series expansion at the approximate coordinates of the SLR station is

$$
\begin{aligned}
\rho_{\mathrm{SLR}}= & \rho_{i}^{0}-\frac{\left(x^{i}-x_{0}\right)}{\rho_{i}^{0}} v_{x}-\frac{\left(y^{i}-y_{0}\right)}{\rho_{i}^{0}} v_{y} \\
& -\frac{\left(z^{i}-z_{0}\right)}{\rho_{i}^{0}} v_{z}+\Delta \rho_{\mathrm{tro}}+\Delta \rho_{\mathrm{scc}} \\
& +\Delta \rho_{\mathrm{rel}}+\Delta \rho_{\mathrm{syms}}+\Delta \rho_{\mathrm{td}}+\Delta \rho_{\mathrm{cm}}
\end{aligned}
$$

where $v_{x}, v_{y}$ and $v_{z}$ are the corrections of the approximate coordinates of SLR station. $\frac{\left(X^{i}-X_{0}\right)}{\rho_{i}^{0}}=l_{i}, \frac{\left(Y^{i}-Y_{0}\right)}{\rho_{i}^{0}}=m_{i}$ and $\frac{\left(Z^{i}-Z_{0}\right)}{\rho_{i}^{0}}=n_{i}$ are the direction cosine from the approximate position of SLR station to the LEO satellite. $\rho_{i}^{0}$ is the geometrical distance from the approximate location of SLR station to the LEO satellite.

When the number of observation epoch is greater than three, the error equation is

$$
v_{i}=-l_{i} v_{x}-m_{i} v_{y}-n_{i} v_{z}+h_{i}
$$

where $i=1,2, \ldots n, n>3$, and $h_{i}=\rho_{i}^{0}-\rho_{\text {slr }}+\Delta \rho_{\text {tro }}+$ $\Delta \rho_{\text {scc }}+\Delta \rho_{\text {rel }}+\Delta \rho_{\text {syms }}+\Delta \rho_{\mathrm{td}}+\Delta \rho_{\text {cm }}$ is the constant term.

$$
\begin{aligned}
& \text { Let } \boldsymbol{V}=\left[v_{1} v_{2} v_{3} \ldots v_{n}\right]^{\mathrm{T}}, \quad \boldsymbol{B}=\left[\begin{array}{ccc}
-l_{1} & -m_{1} & -n_{1} \\
-l_{2} & -m_{2} & -n_{2} \\
-l_{3} & -m_{3} & -n_{3} \\
\vdots & \vdots & \vdots \\
-l_{n} & -m_{n} & -m_{n}
\end{array}\right], \\
& \boldsymbol{P}=\left[\begin{array}{cccc}
p_{1} & 0 & \cdots & 0 \\
0 & p_{2} & \cdots & 0 \\
\vdots & \vdots & \ddots & \vdots \\
0 & 0 & \cdots & p_{n}
\end{array}\right], \quad \boldsymbol{X}=\left[v_{x} v_{y} v_{z}\right]^{T}, \\
& \boldsymbol{H}=\left[\begin{array}{lll}
-h_{1}-h_{2}-h_{3} \cdots-h_{n}
\end{array}\right]^{T} \text {. We can get }
\end{aligned}
$$

$$
\underset{n \times 1}{\boldsymbol{V}}=\underset{n \times 3}{\boldsymbol{B}} \underset{3 \times 1}{\boldsymbol{X}}-\underset{n \times 1}{\boldsymbol{H}}
$$

The least squares method is used to precisely estimate the parameter $\boldsymbol{X}$. The variance of parameter $\boldsymbol{X}$ is

$$
D_{X X}=\left[\begin{array}{ccc}
\sigma_{x_{1}}^{2} & \sigma_{x_{1} x_{2}} & \sigma_{x_{1} x_{3}} \\
\sigma_{x_{2} x_{1}} & \sigma_{x_{2}}^{2} & \sigma_{x_{2} x_{3}} \\
\sigma_{x_{3} x_{1}} & \sigma_{x_{3} x_{2}} & \sigma_{x_{3}}^{2}
\end{array}\right]
$$

where $D_{X X}=\sigma_{0}^{2} Q_{X X}, \sigma_{0}=\sqrt{\frac{V^{T} \boldsymbol{P V}}{n-3}}, Q_{X X}=\left(\boldsymbol{B}^{T} \boldsymbol{P} \boldsymbol{B}\right)^{-1}$.

The parameter $\boldsymbol{X}$ is used to correct the approximate coordinates of SLR station. Equation (4) is repeated until the convergence condition of the iterative calculation is satisfied and the final coordinates of the SLR station and its accuracy are obtained. The priori coordinates of SLR station can be directly solved by using the spatial distance intersection method.

\section{Results and discussion GRACE-A kinematic POD}

We investigated the performance of the method for the estimation of SLR station coordinates by applying it to process GRACE-A data in January-December, 2012. The GRACE-A was taken as the fast-moving stations to complete the estimation of SLR station coordinates. The kinematic orbits of GRACE-A were provided by the Astronomical Institute at the University of Bern (AIUB) (Jäggi et al. 2007; Beutler et al. 2010). The sample rate of kinematic orbit is $30 \mathrm{~s}$, and the 3D precision of POD is up to the level of 3-5 cm (Dach et al. 2009; Zehentner and Mayer-Gürr 2016). According to Eq. (2) in "Methodology" section, the orbit errors of the LEO satellite caused errors in $l_{i}, m_{i}$ and $n_{i}$. This orbit error affected the value of $\rho_{i}^{0}$ in Eq. (2) and generated a constant term error (i.e., $\mathrm{d} h_{i}$, which affected the final result). So, we should obtain the precise orbit of GRACE-A, high-quality SLR data, a good observation geometry and proper offset corrections for the microwave GNSS antenna phase center and for the laser retroreflector offset (see "The estimation of SLR network" section).

The phase (L1P, L2P and L1C) and code (P1, P2 and $\mathrm{C} / \mathrm{A}$ ) observations were available for the POD of GRACE-A. The accurate GPS satellite orbits and clock information processed for GRACE-A were released by the Center for Orbit Determination in Europe (CODE). The kinematic orbit is consistent with the center of mass of the satellite. The kinematic orbit of GRACE-A was in the GPS time (GPST), while the time system of SLR data was the coordinated universal time (UTC). The time systems differ by an integer number of seconds. And the integer difference was $16 \mathrm{~s}$ in July 2012 which is released in IERS Bulletin A.

The Chebyshev polynomial (Bai and Junkins 2011) and linear interpolation (Dach et al. 2015) were used to 
interpolate the kinematic orbits (interval of $30 \mathrm{~s}$ ) to the epoch of SLR measurements. To ensure the accuracy of orbit interpolation, the statistics of RMSs of GRACE-A satellite position at different interpolation interval order and arc length were calculated (see Additional file 1: Table S1). The interval unit is seconds and the orbit fitting interval is $30 \mathrm{~s}$. Compared with the conventional interpolation method, such as the Lagrange and spline functions, the numerical calculation was considerably more stable with the Chebyshev polynomials (Zhan and Liu 2008; Bai and Junkins 2011). From the statistics listed in Additional file 1: Table S1, we inferred that in the case of the same polynomial order, the longer track lengths we select, the lower accuracy of results we get. For the same track length, as the polynomial order increased, the accuracy of results gradually was improved. However, this did not imply that the high order of polynomial was reasonable. Because of the limitation of kinematic orbit accuracy of GRACE-A, there was no practical significance of increasing the polynomial order after the orbit reached a certain accuracy. Moreover, it was necessary to invert the normal equation when calculating the undetermined coefficients. If the order was too high, the normal equation would not be applicable. Therefore, the suitable arc length and order are important for orbit interpolation.

\section{Preprocessing of SLR data}

The SLR stations used in the study are listed in Table 1. The SLR normal point (NP) data of GRACE-A were obtained from the ILRS, and the SLR observations are used above the elevation angle of $10^{\circ}$. The SLR stations which tracked the GRACE-A in 2012 are shown in Fig. 3. It is difficult to track GRACE-A by SLR sites because of the short passes of the satellite with orbital altitudes of $330-450 \mathrm{~km}$. So, the SLR NPs are relatively rare. Figure 3 shows the ground distribution of the selected SLR sites. There are 10 sites with fewer than 1000 NPs, and only three of SLR sites collected more than 3000 NPs. The Yarragadee station (7090) is the only site with greater than 5000 NPs. The poor geometry of SLR network leads to the results of about $74 \%$ sites located on the northern hemisphere. The sites on the southern hemisphere collected in total 17,186 NPs, i.e., almost $43 \%$ of the observations.

The LRA onboard GRACE-A consists of 4 coated corner cubes with a regular $45^{\circ}$ pyramid, and the

Table 1 Estimated SLR stations position corrections in east (e), north (n), and up (u) direction compared to SLRF2014 and range biases $(b)$ with a sigma

\begin{tabular}{|c|c|c|c|c|c|c|}
\hline Site ID & Location & $n(\mathrm{~mm})$ & $e(\mathrm{~mm})$ & $u(\mathrm{~mm})$ & $b(\mathrm{~mm})$ & $N_{\mathrm{np}}$ \\
\hline 1824 & Golosiiv & $4.1 \pm 2.6$ & $-12.4 \pm 2.4$ & $-15.3 \pm 6.9$ & $-9.5 \pm 5.4$ & 224 \\
\hline 1879 & Altay & $-2.6 \pm 2.9$ & $8.7 \pm 2.5$ & $56.8 \pm 6.3$ & $-16.8 \pm 5.3$ & 243 \\
\hline 1884 & Riga & $-10.3 \pm 2.7$ & $-7.1 \pm 1.6$ & $83.7 \pm 5.4$ & $57.4 \pm 5.1$ & 377 \\
\hline 7090 & Yarragadee & $2.1 \pm 0.3$ & $-3.1 \pm 0.4$ & $6.9 \pm 0.9$ & $4.1 \pm 0.7$ & 8554 \\
\hline 7105 & Greenbelt & $1.9 \pm 0.8$ & $-2.4 \pm 0.6$ & $-11.3 \pm 1.2$ & $-11.4 \pm 1.1$ & 3429 \\
\hline 7110 & Monument Peak & $8.2 \pm 1.3$ & $-1.6 \pm 0.9$ & $-27.1 \pm 2.8$ & $-3.9 \pm 1.6$ & 1788 \\
\hline 7119 & Haleakala & $-1.8 \pm 1.5$ & $14.6 \pm 1.1$ & $-28.9 \pm 3.9$ & $-15.2 \pm 3.6$ & 695 \\
\hline 7124 & Tahiti & $5.4 \pm 2.8$ & $-13.6 \pm 2.4$ & $-53.4 \pm 5.9$ & $-9.3 \pm 5.3$ & 246 \\
\hline 7237 & Changchun & $-8.6 \pm 0.9$ & $12.1 \pm 0.8$ & $15.4 \pm 1.9$ & $4.1 \pm 1.2$ & 2482 \\
\hline 7249 & Beijing & $-15.8 \pm 1.5$ & $16.3 \pm 1.8$ & $27.4 \pm 4.9$ & $-8.3 \pm 4.2$ & 493 \\
\hline 7403 & Arequipa & $-7.8 \pm 1.3$ & $11.3 \pm 1.4$ & $27.9 \pm 3.7$ & $17.8 \pm 2.9$ & 1284 \\
\hline 7406 & San Juan & $-8.9 \pm 1.0$ & $-10.3 \pm 0.9$ & $-17.4 \pm 2.5$ & $-11.8 \pm 1.5$ & 2030 \\
\hline 7501 & Hartebeesthoek & $-4.5 \pm 1.4$ & $2.9 \pm 1.1$ & $-17.6 \pm 3.3$ & $-6.7 \pm 2.2$ & 1516 \\
\hline 7810 & Zimmerwald & $1.3 \pm 0.7$ & $-2.9 \pm 0.6$ & $5.2 \pm 1.1$ & $3.0 \pm 1.0$ & 4095 \\
\hline 7821 & Shanghai & $-11.4 \pm 1.4$ & $-4.5 \pm 1.7$ & $59.2 \pm 4.4$ & $-13.3 \pm 3.9$ & 505 \\
\hline 7824 & San Fernando & $-12.3 \pm 1.7$ & $-13.7 \pm 1.6$ & $50.1 \pm 4.0$ & $-20.1 \pm 3.4$ & 778 \\
\hline 7825 & Mt. Stromlo & $2.8 \pm 0.8$ & $3.6 \pm 0.7$ & $-8.2 \pm 1.3$ & $15.7 \pm 1.1$ & 3339 \\
\hline 7838 & Simosato & $-13.2 \pm 2.2$ & $9.4 \pm 1.9$ & $-62.2 \pm 5.3$ & $9.2 \pm 4.5$ & 434 \\
\hline 7839 & Graz & $-1.4 \pm 1.1$ & $1.9 \pm 1.0$ & $18.1 \pm 2.9$ & $-2.5 \pm 1.9$ & 1718 \\
\hline 7840 & Herstmonceux & $1.4 \pm 1.1$ & $7.6 \pm 1.2$ & $7.2 \pm 3.5$ & $-5.8 \pm 2.5$ & 1468 \\
\hline 7841 & Potsdam & $10.1 \pm 1.0$ & $-0.8 \pm 0.8$ & $25.6 \pm 2.1$ & $8.5 \pm 1.3$ & 2111 \\
\hline 7941 & Matera & $-4.1 \pm 1.1$ & $-9.8 \pm 1.4$ & $36.3 \pm 4.3$ & $-5.2 \pm 3.7$ & 668 \\
\hline 8834 & Wettzel & $3.4 \pm 1.2$ & $-4.1 \pm 1.0$ & $-27.6 \pm 3.2$ & $-15.7 \pm 2.2$ & 1518 \\
\hline
\end{tabular}

All values are on the basis of January-December 2012 and refer to the mean epoch 2012.5. In addition, the number of normal points $\left(N_{\text {np }}\right)$ is given and no timing bias corrections were applied 


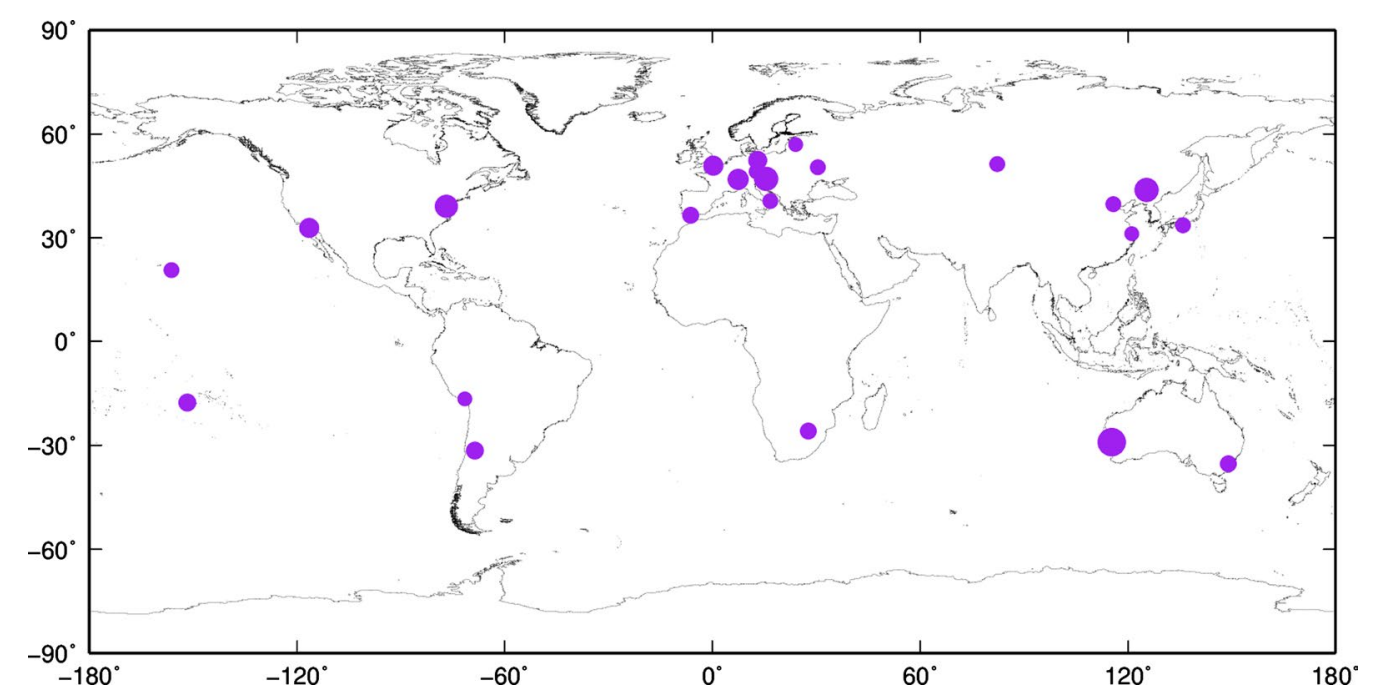

Fig. 3 Ground distribution of SLR sites. Only the GRACE-A satellite was tracked (the number of SLR NPs is consistent with the size of marker)

diameter of array is $10 \mathrm{~cm}$. The vectors of the laser reflector position and the GPS receiver antenna phase center of GRACE-A in the satellite-fixed coordinate system are $S_{\mathrm{SLR}}=(-0.6000,-0.3275,-0.2178)$ and $S_{\mathrm{GPS}}=(-0.0004,-0.0004,-0.4516)$, respectively. The LRA-CoM offset vector and the LRA range correction (Neubert 2009) provided by the recommendations of the ILRS Analysis Working Group (AWG) were used in the adjustment of CoM correction (Neubert 2009). The GRACE-A Level-1B star camera data (SCA1B) (Bettadpur 2012) [attitude quaternions describing the true (rather than nominal) orientation of the spacecraft body frame] provided by the Information System and Data Center (ISDC) at the German Research Center for Geosciences at Potsdam (GFZ) were used to achieve the highprecision results. The ILRS data handling file derived from AWG were used in Bernese Software V5.2 (Dach et al. 2015) for data preprocessing. The Bernese Software v5.2 is a well-tested software and is capable to process both data types, i.e., GNSS and SLR. The software is capable to perform the SLR analysis obeying the state-ofthe-art models and guidelines for SLR (Thaller et al. 2011; Dach et al. 2015; Bruni et al. 2017; Otsubo et al. 2018).

The space-time curvature correction (Petit and Luzum 2010) is applied. Mendes-Pavlis zenith delay model (Mendes et al. 2002; Mendes and Pavlis 2004) is used to compute the tropospheric delay corrections. The satellite-specific information was obtained from the laser reflector user manual provided by GFZ (Tapley et al.
2004), and the satellite-specific information is produced by Astronomical Institute at the University of Bern (AIUB) (Dach et al. 2015), which is provided in SATELLIT.I08 product.

\section{The estimation of SLR network}

In contrast to the dynamic method, all SLR station positions can be set as free parameters in the adjustment. The Earth orientation parameters (EOPs), tropospheric parameters and satellite orbit parameters are processed as fixed parameters in the estimation. The SLR observations are equally weighted. The implicit geodetic datum of kinematic orbits of the GRACE-A derived from GPS observations and GPS orbit products is the International GNSS Service Reference Frame (IGS08/IGb08) (Dow et al. 2009). The GPS-derived kinematic orbits implicitly contain information on the gravity field and geocenter motion (Dow et al. 2009; Beutler et al. 2010). The SLR station position is tied to the SLR-specific realization (SLRF). In brief, Eqs. (1) and (2) imply that LEO satellite and station positions are referred to a unified reference frame. In practice, the request can hardly be met. It is well known that the technique-dependent reference frames contribute to a common release of the International Terrestrial Reference Frame (e.g., IGS08 and SLRF2008 for ITRF2008). Generally, the associated differences can be ignored while working with corresponding frames (Altamimi et al. 2016; Arnold et al. 2018). The classical SLR residuals analysis method (Combrinck 
2010; Appleby et al. 2016; Arnold et al. 2018) is applied to estimate range biases and timing offset. Table 1 illustrates position and range bias corrections for the SLRF2014 (ILRS 2018). Appleby et al. (2016) indicated that SLR timing bias should not be estimated in 2012. So, no timing bias corrections are listed in Table 1.

The summary of coordinates and range bias corrections for SLRF2014 is listed in Table 1. The estimated results of most SLR stations are relatively reasonable, except for individual stations that cannot be solved due to insufficient number of observations. The results of most sites in the horizontal direction are better than those in the vertical direction. For stations Beijing (7249) and San Fernando (7824), the large discrepancies occurred in vertical/horizontal directions. Those stations with high performance and productivity have much better estimation results such as Yarragadee (7090), Zimmerwald (7810) and Greenbelt (7105). It is clear that the mean level of estimated results is highly influenced by these stations with large discrepancies, e.g., Riga (1884), San Simosato (7824). For some of them, the large discrepancies in position always occur with large range biases. These large range biases are consistent with results reported independently in an ILRS-like processing of data to the geodetic satellites LAGEOS-1 and LAGEOS-2 (Appleby et al. 2016; Otsubo 2018) and LEO satellites (Arnold et al. 2018).

Figure 4 shows the direct coordinate comparison with SLRF2008/SLRF2014 (ILRS 2016) by using the absolute differences. The agreement level of the results for SLRF2014 is better than that of results for SLRF2008 because of the data span of ITRF2008 ending in 2009. This is in line with the result of Arnold et al. (2018), Sośnica et al. (2018) and Zelensky et al. (2018) about the reference of ITRF2008 when extrapolated over the end of solution in 2009. Specifically, the observations used in the estimation are far apart from January 1, 2005 (i.e., the reference epoch of the ITRF2008) (Altamimi et al. 2011; Rebischung et al. 2012). The average agreement with SLRF2014 for all SLR stations is $32 \mathrm{~mm}$. However, the large discrepancies were shown in few sites, e.g., Simosato (7838), Altay (1879) and Riga (1884). In brief, the prerequisite for reasonable coordinate estimates is the adequate SLR NPs. The minimum requirement of the number of SLR NPs to acquire stable estimated solutions for SLR sites is about 100-200 in a month. These stations, which collected sufficient number of SLR NPs, agree with SLRF2014 with the mean level of $21 \mathrm{~mm}$. For the SLR sites whose SLR-to-LEO data are not available all year round, the agreement level varies substantially like Tahiti (7124) and Golosiiv (1824). Figure 5 shows the position differences before and after the correction of range bias. The average agreement level of all sites compared with SLRF2014 improved by $5 \mathrm{~mm}$ while the range bias correction was applied. The improvement varies substantially from site to site, and the agreement performance of 5 SLR sites has evidently improved. The coordinate estimation for San Fernando (7824) and Wettzel (8834) improved by $10-12 \mathrm{~mm}$.

An ideal observation geometry is consistent with the rich SLR observations. Figure 6 illustrates the 1-year distribution of SLR observations to GRACE-A provided by

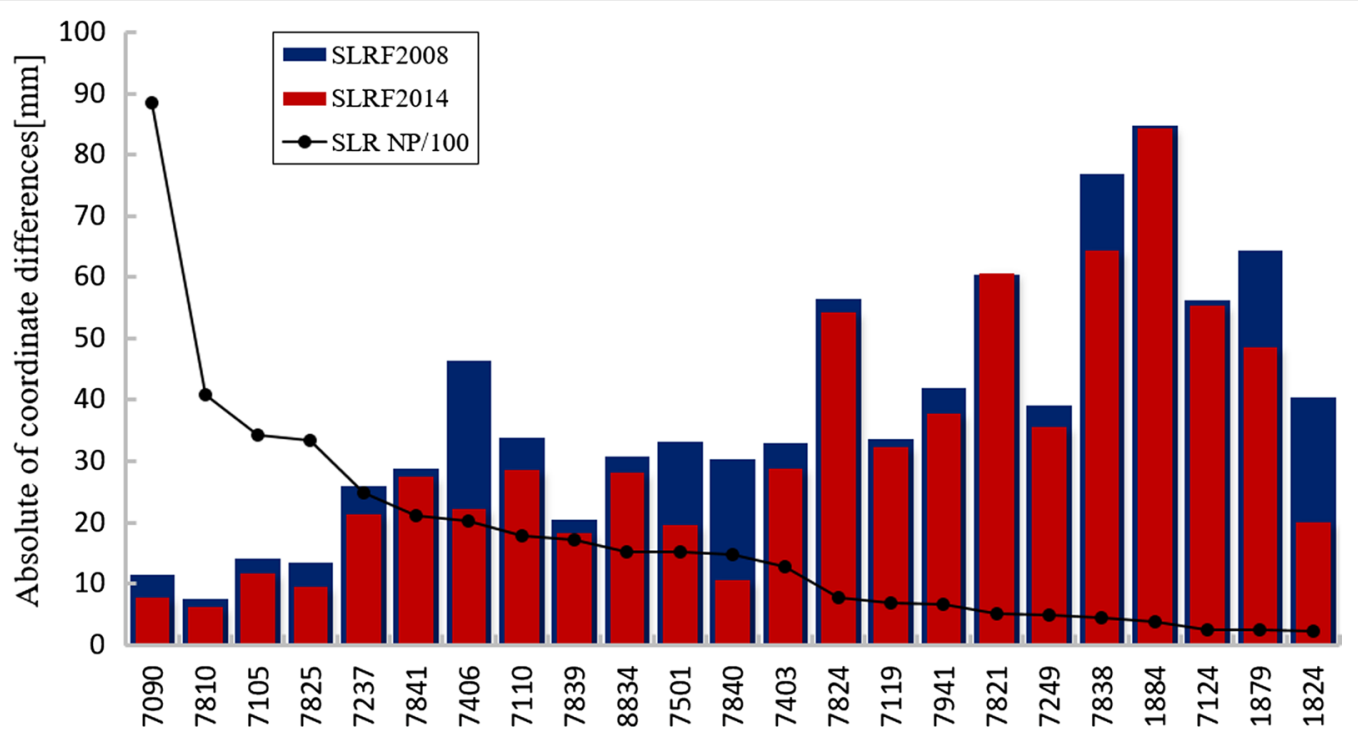

Fig. 4 Absolute of coordinate differences between the estimated SLR station coordinates and SLRF2008 and SLRF2014. The range bias corrections were applied in estimation 


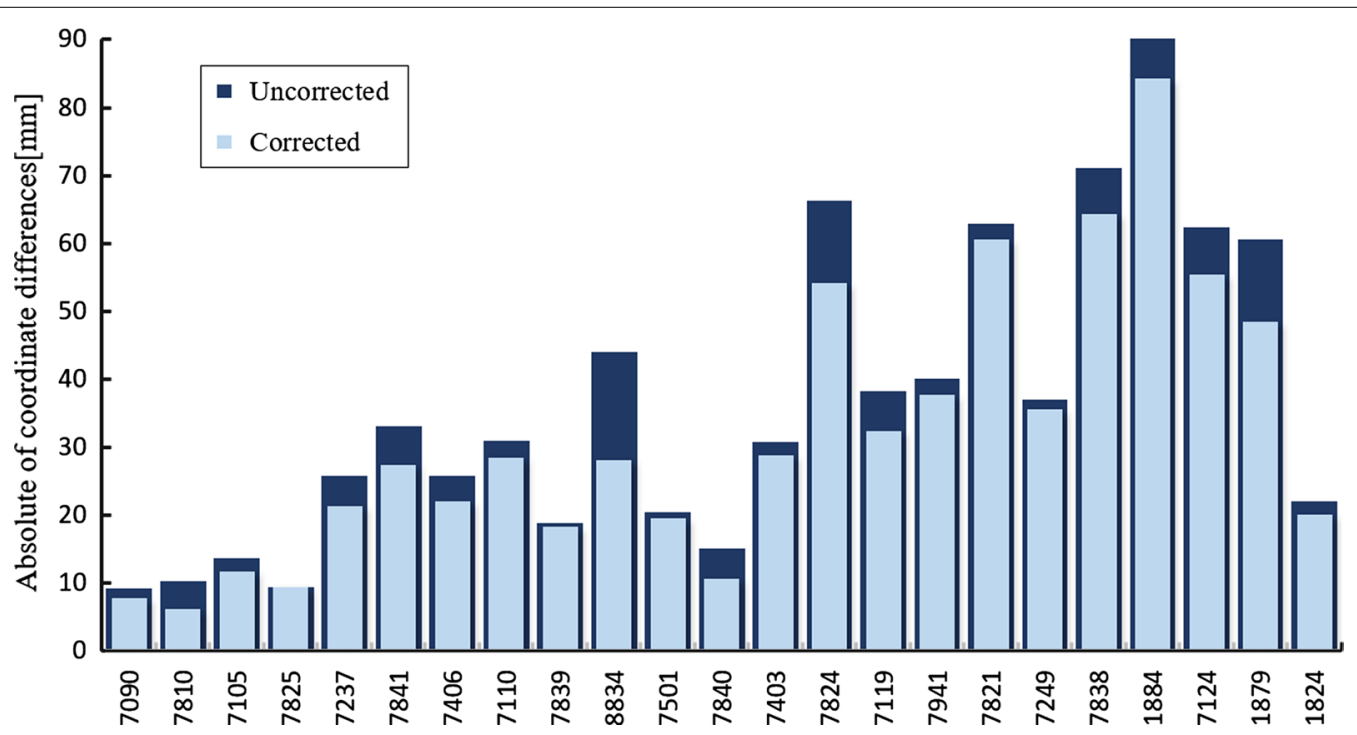

Fig. 5 Coordinate differences between the estimated SLR station coordinates and ITRF2014 before/after applying corrections of the range bias

some typical SLR sites. It is clear that the stations with large number of SLR NPs own the reasonable observation distribution which results in the great agreement with SLRF2014, e.g., Yarragadee (7090), Zimmerwald (7810) and Greenbelt (7105). The observation geometry is quite well for Herstmonceux (7840), and the correlation is evidently reduced. For Riga (1884), the distribution is not as homogeneous. GRACE-A satellite followed the identical ground track for several passes which implies that the observation geometry is the same. In addition to high performance and productivity, the reasonable observation geometry is also a necessary guarantee of the coordinate estimation for the SLR sites.

For those SLR stations with reasonable number of observations, the agreement with SLRF2014 is at the mean level of $21 \mathrm{~mm}$. This result indicates that it is feasible to precisely estimate the position of SLR stations by this kinematic method. The results show that the direct way of attaching the SLR station to IGS network by this method works well.

\section{Conclusions}

In this work, we demonstrated a kinematic method of estimating the coordinates of SLR stations by using LEO satellite to directly attach the SLR network to the GNSSderived TRF. This method estimates the coordinates of SLR station and provides a strong tie between SLR and GNSS space techniques.

The average agreement level of the estimated results compared with SLRF2014 solutions was $21 \mathrm{~mm}$ for SLR sites with the reasonable number of observations over a period of 1 year. This method allows a direct connection of the IGS network and the SLR network at the centimeter level. If we add LEO satellites and the SLR tracking arcs to obtain more observations, the results will be better. 


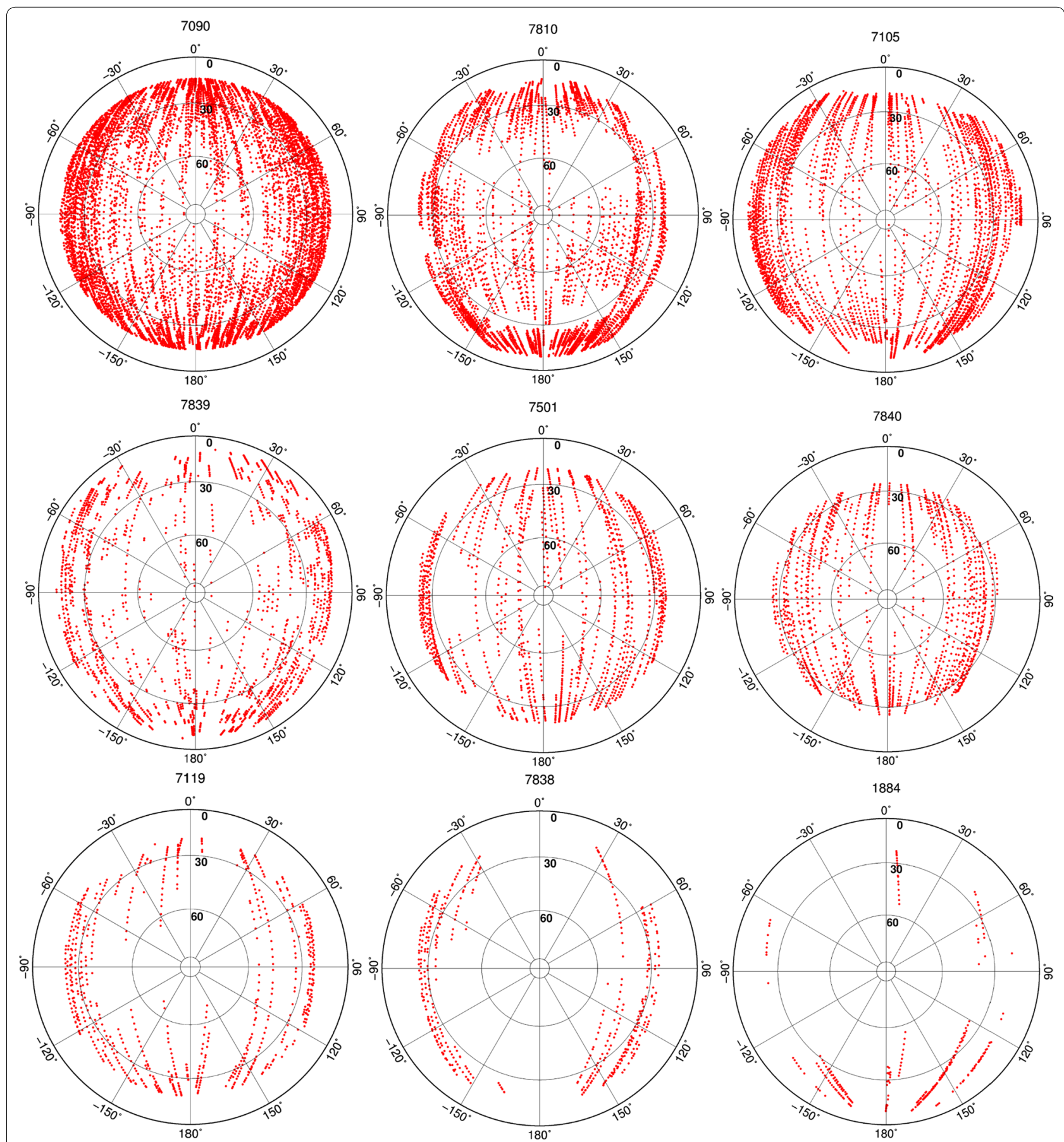

Fig. 6 SLR observation distribution of the GRACE-A taken by SLR sites seen in the station-fixed system (azimuth and elevation angle)

This study provided not only a method for determining the coordinates of SLR stations, but also an idea for the combination of different space geodetic techniques at the satellite level. It is of great significance to establish and maintain the ITRF at the LEO satellite level.

\section{Additional file}

Additional file 1: Table S1. Statistics of the RMS of the GRACE-A satellite orbits at different interpolation orders and arc length (unit: $\mathrm{m}$ ). 


\begin{abstract}
Abbreviations
SLR: Satellite laser ranging; GNSS: Global navigation satellite system; LEO: Low Earth orbiting; ITRF: International Terrestrial Reference Frame; ITRS: International Terrestrial Reference System; IERS: International Earth Rotation and Reference Systems Service; IUGG: International Union of Geodesy and Geophysics; VLBI: Very long baseline interferometry; DORIS: Doppler orbitography radiopositioning integrated by satellite; IAG: International Association of Geodesy; IGS: International GNSS Service; ISDC: Information System and Data Center; ILRS: International Laser Ranging Service; POD: Precise orbit determination; CoM: Center of mass; UTC: Universal time; GPST: Global Positioning System time; ACV: Antenna center variation; PCV: Phase center variations; CODE: Center for Orbit Determination in Europe; NP: Normal point; GFZ: Deutsche Geo ForschungsZentrum.
\end{abstract}

\section{Authors' contributions}

$J G, Y W$ and $Y S$ designed and performed experiments, analyzed data and drafted the manuscript; JG encouraged YW to investigate the space geodetic colocated technique. YW carried out the data analysis and YS prepared the manuscript. All authors have contributed to the interpretation of the results. All authors read and approved the final manuscript.

\section{Author details}

${ }^{1}$ College of Geodesy and Geomatics, Shandong University of Science and Technology, Qingdao 266590, China. ${ }^{2}$ State Key Laboratory of Mining Disaster Prevention and Control Cofounded by Shandong Province and Ministry of Science and Technology, Shandong University of Science and Technology, Qingdao 266590, China. ${ }^{3}$ Key Laboratory of Spatial Data Mining and Information Sharing of Education Ministry, Fuzhou University, Fuzhou 350116, China.

\section{Acknowledgements}

We are very grateful to the International Earth Rotation and Reference Systems Service for providing the time data. The data of GRACE-A are supported by the Center for Orbit Determination in Europe and the Information System and Data Center at the German Research Center for Geosciences at Potsdam. ILRS is acknowledged for providing the SLR observations of GRACE-A.

\section{Competing interests}

The authors declare that they have no competing interests.

\section{Consent for publication}

Not applicable.

\section{Availability of data and materials}

The time data about GPST and UTC are available at https://www.iers.org/IERS/ EN/Home/home_node.html. The orbit data of the GRACE-A are obtained from $\mathrm{ftp}: / / \mathrm{ftp}$.aiub.unibe.ch/LEO_ORBITS/. The attitude data of the GRACE-A are downloaded from http://isdc-old.gfz-potsdam.de/index.php. The SLR observations are provided by the https://ilrs.cddis.eosdis.nasa.gov/data_and_produ $\mathrm{cts} /$ data/index.html. The SLRF2014 station coordinates are obtained from ftp:// cddis.gsfc.nasa.gov/sIr/products/resource/SLRF2014_POS+VEL_2030.0_18050 4.snx.

\section{Ethics approval and consent to participate}

Not applicable.

\section{Funding}

This work is supported by the National Natural Science Foundation of China (Grant Nos. 41774001, 41704015 and 41374009), the Special Project of Basic Sci. and Tech. of China (Grant No. 2015FY310200) and the SDUST Research Fund (Grant No. 2014TDJH101)

\section{Publisher's Note}

Springer Nature remains neutral with regard to jurisdictional claims in published maps and institutional affiliations.

Received: 26 May 2018 Accepted: 10 December 2018 Published online: 19 December 2018

\section{References}

Altamimi Z, Collilieux X, Legrand J, Garayt B, Boucher C (2007) ITRF2005: a new release of the International Terrestrial Reference Frame based on time series of station positions and Earth orientation parameters. J Geophys Res 112:B09401. https://doi.org/10.1029/2007JB004949

Altamimi Z, Collilieux X, Métivier L (2011) ITRF2008: an improved solution of the International Terrestrial Reference Frame. J Geod 85(8):457-473. https ://doi.org/10.1007/s00190-011-044

Altamimi Z, Rebischung P, Métivier L, Collilieux X (2016) ITRF2014: a new release of the International Terrestrial Reference Frame modeling nonlinear station motions. J Geophys Res Solid Earth 121(8):6109-6131. https:// doi.org/10.1002/2016JB013098

Appleby G, Rodríguez J, Altamimi Z (2016) Assessment of the accuracy of global geodetic satellite laser ranging observations and estimated impact on ITRF scale: estimation of systematic errors in LAGEOS observations 1993-2014. J Geod 90:1371. https://doi.org/10.1007/s00190-016-0929-2

Arnold D, Montenbruck O, Hackel S, Sośnica K (2018) Satellite laser ranging to low Earth orbiters: orbit and network validation. J Geod. https://doi. org/10.1007/s00190-018-1140-4

Bai XL, Junkins JL (2011) Modified Chebyshev-Picard iteration methods for orbit propagation. J Astronaut Sci 58(4):583-613. https://doi.org/10.1007/ BF03321533

Beutler G, Jäggi A, Meyer U, Mervart L (2010) The celestial mechanics approach: application to data of the GRACE mission. J Geod 84:661-681. https://doi.org/10.1007/s00190-010-0402-6

Bruni S, Rebischung P, Zerbini S, Altamimi Z, Errico M, Santi E (2017) Assessment of the possible contribution of space ties on-board GNSS satellites to the terrestrial reference frame. J Geod 92:383. https://doi.org/10.1007/ s00190-017-1069-z

Combrinck L (2010) Satellite laser ranging. In: Xu G (ed) Sciences of geodesyI. Springer, Berlin, pp 301-338. https://doi.org/10.1007/978-3-642-11741 $-1 \_9$

Coulot D, Pollet A, Collilieux X (2010) Global optimization of core station networks for space geodesy: application to the referencing of the SLR EOP with respect to ITRF. J Geod 84:31-50. https://doi.org/10.1007/s0019 $0-009-0342-1$

Dach R, Brockmann E, Schaer S, Beutler G, Meindl M, Prange L, Bock H, Jäggi A, Ostini L (2009) GNSS processing at CODE: status report. J Geod 83(3-4):353-365. https://doi.org/10.1007/s00190-008-0281-2

Dach R, Lutz S, Walser P, Fridez P (2015) Bernese GNSS Software Version 5.2. User manual; Astronomical Institute, Faculty of Science, University of Bern, Bern, Switzerland. Bern Open Publishing. http://www.berne se.unibe.ch. Accessed 15 Aug 2018

Dow JM, Neilan RE, Rizos C (2009) The International GNSS Service in a changing landscape of Global Navigation Satellite Systems. J Geod 83(3-4):191-198. https://doi.org/10.1007/s00190-008-0300-3

Ebauer K (2017) Development of a software package for determination of geodynamic parameters from combined processing of SLR data from LAGEOS and LEO. Geod Geodyn 8(3):213-220. https://doi. org/10.1016/j.geog.2017.03.004

Ge M, Gendt G, Dick G, Zhang F, Reigber C (2005) Impact of GPS satellite antenna offsets on scale changes in global network solutions. Geophys Res Lett 32:L06310. https://doi.org/10.1029/2004GL022224

Glaser S, Fritsche M, Sośnica K, Rodríguez-Solano CJ, Wang K, Dach R, Hugentobler U, Rothacher M, Dietrich R (2015) Validation of components of local ties. In: van Dam T (ed) REFAG 2014. International Association of Geodesy Symposia, vol 146. Springer, Cham, pp 21-28. https://doi.org/10.1007/1345_2015_190

Gong XQ, Shen YZ, Wang JX, Wu B, You XZ, Chen JP (2014) Surveying colocated GNSS, VLBI, and SLR stations in China. J Surv Eng 140(1):28-34. https://doi.org/10.1061/(ASCE)SU.1943-5428.0000118

Guo JY, Qin J, Kong QL, Li GW (2012) On simulation of precise orbit determination of HY-2 with centimeter precision based on satellite-borne GPS technique. Appl Geophys 9(1):95-107. https://doi.org/10.1007/s1177 0-012-0319-3

Guo J, Kong Q, Qin J, Sun Y (2013) On precise orbit determination of HY-2 with space geodetic techniques. Acta Geophys 61(3):752-772. https:// doi.org/10.2478/s11600-012-0095-8 
Hellerschmied A, McCallum L, McCallum J, Sun J, Böhm J, Cao JF (2018) Observing APOD with the AuScope VLBI array. Sensors 18:1587. https:// doi.org/10.3390/s18051587

ILRS (2018) SLRF2014 station coordinates. ftp://cddis.gsfc.nasa.gov/slr/ products/resource/SLRF2014_POS+VEL_2030.0_180504.snx

ILRS Analysis Standing Committee (2016) SLRF2008. https://ilrs.cddis.eosdi s.nasa.gov/science/awg/SLRF2008.html Accessed 20 Nov 2018

Jäggi A, Hugentobler U, Bock H, Beutler G (2007) Precise orbit determination for GRACE using undifferenced or doubly differenced GPS data. Adv Space Res 39(10):1612-1619. https://doi.org/10.1016/j.asr.2007.03.012

Krügel M, Angermann D (2005) Analysis of local ties from multiyear solutions of different techniques. In: Richter B, Dick W, Schwegmann W (eds) Proceedings of the IERS workshop on site co-locations, Verlag des BundesamtsfürKartographie und Geodäsie, Frankfurt am Main, Germany, IERS Technical Note, no. 33

Li JC, Zhang SJ, Zou XC, Jiang WP (2009) Precise orbit determination for GRACE with zero-difference kinematic method. Chin Sci Bull 54(16):2355-2362. https://doi.org/10.1007/s11434-009-0286-0 (in Chinese)

Mendes VB, Pavlis EC (2004) High-accuracy zenith delay prediction at optical wavelengths. Geophys Res Lett 31:14602. https://doi. org/10.1029/2004GL020308

Mendes VB, Prates G, Pavlis EC, Pavlis D, Langley RB (2002) Improved mapping functions for atmospheric refraction correction in SLR. Geophys Res Lett 29(10):1414. https://doi.org/10.1029/2001GL014394

Munghemezulu C, Combrinck L, Mayer D, Botai OJ (2014) Comparison of site velocities derived from collocated GPS, VLBI and SLR techniques at the Hartebeesthoek Radio Astronomy Observatory (comparison of site velocities). J Geod Sci 4:1-7. https://doi.org/10.2478/jogs-2014-0002

Neubert R (2009) The center of mass correction (CoM) for laser ranging data of the CHAMP reflector, Issue c, 14 Oct 2009. https://ilrs.cddis.eosdi s.nasa.gov/docs/CH_GRACE_COM_c.pdf

Otsubo T (2018) Multi-satellite bias analysis report v2 for worldwide satellite laser ranging stations. http://geo.science.hit-u.ac.jp/slr/bias/. Accessed 20 Oct 2018

Otsubo T, Matsuo K, Aoyama Y, Yamamoto K, Hobiger T, Kubo-okaT Sekido M (2016) Effective expansion of satellite laser ranging network to improve global geodetic parameters. Earth Planets Space 68:65. https ://doi.org/10.1186/s40623-016-0447-8

Otsubo T, Müller H, Pavlis EC, Torrence MH, Thaller D, Glotov VD, Wang X, Sośnica K, Meyer U, Wilkinson MJ (2018) Rapid response quality control service for the laser ranging tracking network. J Geod. https://doi. org/10.1007/s00190-018-1197-0

Pearlman MR, Degnan JJ, Bosworth JM (2002) The International Laser Ranging Service. Adv Space Res 30(2):135-143. https://doi.org/10.1016/S0273 $-1177(02) 00277-6$

Petit G, Luzum B (2010) IERS conventions (2010). IERS Technical Note no. 36, Verlag des BundesamtsfürKartographie und Geodäsie, Frankfurt

Ray J (2000) Towards an integrated global geodetic observing system: geodesy as a utility. In: Rummel R, Drewes H, Bosch W, Hornik H (eds) Towards an integrated global geodetic observing system (IGGOS). IAG symposium 120. Springer, Berlin, pp 19-21

Rebischung P, Griffiths J, Ray J, Collilieux X, Garayt B (2012) IGS08: the IGS realization of ITRF2008. GPS Solut 16(4):483-494. https://doi.org/10.1007/ s10291-011-0248-2

Rebischung P, Altamimi Z, Ray J, Garayt B (2016) The IGS contribution to ITRF2014. J Geod 90(7):611-630. https://doi.org/10.1007/s0019 0-016-0897-6

Rothacher M (2000) Towards an integrated global geodetic observing system. In: Rummel R, Drewes H, Bosch W, Hornik H (eds) Towards an integrated global geodetic observing system (IGGOS). IAG symposium 120. Springer, Berlin, pp 41-52

Sarti P, Sillard P, Vittuari L (2004) Surveying co-located space-geodetic instruments for ITRF computation. J Geod 78:210-222. https://doi.org/10.1007/ s00190-004-0387-0
Schillak S, Wnuk E (2003) The SLR stations coordinates determined from monthly arcs of LAGEOS-1 and LAGEOS-2 laser ranging in 1999-2001. Adv Space Res 31:1935-1940. https://doi.org/10.1016/S0273 $-1177(03) 00169-8$

Schlüter W, Behrend D (2007) The International VLBI Service for Geodesy and Astrometry (IVS): current capabilities and future prospects. J Geod 81(6-8):379-387. https://doi.org/10.1007/s00190-006-0131-z

Schmid R, Steigenberger P, Gendt G, Ge M, Rothacher M (2007) Generation of a consistent absolute phase center correction model for GPS receiver and satellite antennas. J Geod 81(12):781-798. https://doi.org/10.1007/s0019 0-007-0148-y

Shen Y, Guo JY, Zhao CM, Yu XM, Li JL (2015) Earth rotation parameter and variation during 2005-2010 solved with LAGEOS SLR data. Geod Geodyn 6(1):55-60. https://doi.org/10.1016/j.geog.2014.12.002

Sośnica K, Thaller D, Dach R, Steigenberger P, Beutler G, Arnold D, Jäggi A (2015) Satellite laser ranging to GPS and GLONASS. J Geod 89(7):725-743. https://doi.org/10.1007/s00190-015-0810-8

Sośnica K, Bury G, Zajdel R (2018) Contribution of multi-GNSS constellation to SLR-derived terrestrial reference frame. Geophys Res Lett 45:2339-2348. https://doi.org/10.1002/2017GL076850

Švehla D, Rothacher M (2003) Kinematic and reduce-dynamic precise orbit determination of low earth orbiters. Adv Geosci 1:47-56. https://doi. org/10.5194/adgeo-1-47-2003

Tapley BD, Bettadpur S, Watkins M, Reigber C (2004) The gravity recovery and climate experiment: mission overview and early results. Geophys Res Lett 31:L09607. https://doi.org/10.1029/2004gl019920

Thaller D, Dach R, Seitz M, Beutler G, Mareyen M, Richter B (2011) Combination of GNSS and SLR observations using satellite co-locations. J Geod 85(5):257-272. https://doi.org/10.1007/s00190-010-0433-z

Thaller D, Sośnica K, Steigenberger P, Roggennbuck O (2015) Pre-combined GNSS-SLR solutions what could be the benefit for the ITRF? In: van Dam T (ed) REFAG 2014. IAG Symposium, vol 146. Springer, Cham, pp 85-94. https://doi.org/10.1007/1345_2015_215

Tseng TP, Hwang C, Sośnica K, Kuo CY, Liu YC, Yeh WH (2017) Geocenter motion estimated from GRACE orbits: the impact of F10.7 solar flux. Adv Space Res 59:2819-2830. https://doi.org/10.1016/j.asr.2016.02.003

Willis P, Fagard H, Ferrage P, Lemoine FG, Noll CE, Noomen R, Otten M, Ries JC, Rothacher M, Soudarin L, Tavernier G, Valette JJ (2010) The International DORIS Service, toward maturity. Adv Space Res 45(12):1408-1420. https:// doi.org/10.1016/j.asr.2009.11.018

Zehentner N, Mayer-Gürr T (2016) Precise orbit determination based on raw GPS measurements. J Geod 90(3):275-286. https://doi.org/10.1007/s0019 0-015-0872-7

Zelensky NP, Lemoine FG, Beckley BD, Chinn DS, Pavlis DE (2018) Impact of ITRS 2014 realizations on altimeter satellite precise orbit determination. Adv Space Res 61(1):45-73. https://doi.org/10.1016/j.asr.2017.07.044

Zhan RW, Liu GY (2008) Discussion on orbit fitting and orbit forecasting of low Earth orbit satellites. J Geod Geodyn 28(4):115-120. https://doi. org/10.14075/j.jgg.2008.04.005 (in Chinese)

\section{Submit your manuscript to a SpringerOpen ${ }^{\circ}$ journal and benefit from:}

- Convenient online submission

- Rigorous peer review

- Open access: articles freely available online

- High visibility within the field

- Retaining the copyright to your article

Submit your next manuscript at springeropen.com 